\title{
Efficacy of Prednisolone in Recovery from Acute Bronchiolitis: Study in a Tertiary Care Hospital, Dhaka, Bangladesh
}

\author{
Khondaker Zahirul Hasan ${ }^{1}$, Md. Abid Hossain Mollah², Mohammad Monir Hossain ${ }^{3}$, \\ Muhammad Zahangir Alam ${ }^{1}$, A. N. M. Shahidul Islam Bhuiyan ${ }^{4}$, Md. Faruk Ahmed ${ }^{5}$, \\ Md. Iftekhar-ul-Haque Khan ${ }^{6}$
}

${ }^{1}$ Department of Pediatrics, Abdul Malek Ukil Medical College, Noakhali, Bandladesh
${ }^{2}$ Department of Pediatrics, Ibrahim Medical College, Dhaka, Bangladesh
${ }^{3}$ Department of Pediatrics, Sylhet MAG Osmani Medical College, Sylhet, Bandladesh
${ }^{4}$ Department of Pediatrics, Cumilla Medical College Hospital, Cumilla, Bangladesh
${ }^{5}$ Department of Pediatrics, Sheikh Sayera Khatun Medical College, Gopalgonj, Bangladesh
${ }^{6}$ Department of Pediatrics, Cumilla Medical College, Cumilla, Bangladesh

Email address:

zahirulh@yahoo.com (Hasan KZ)

\section{To cite this article:}

Khondaker Zahirul Hasan, Md. Abid Hossain Mollah, Mohammad Monir Hossain, Muhammad Zahangir Alam, A. N. M. Shahidul Islam Bhuiyan, Md. Faruk Ahmed, Md. Iftekhar-ul-Haque Khan. Efficacy of Prednisolone in Recovery from Acute Bronchiolitis: Study in a Tertiary Care Hospital, Dhaka, Bangladesh. American Journal of Pediatrics. Vol. 7, No. 2, 2021, pp. 85-90. doi: 10.11648/j.ajp.20210702.19

Received: February 13, 2021; Accepted: April 21, 2021; Published: June 4, 2021

\begin{abstract}
Introduction: Acute bronchiolitis is a condition where patients are presenting with breathing difficulties, cough, poor feeding, and irritability. Treatment of bronchiolitis have many controversies. Most trials of bronchiolitis treatment suffer from 2 constraints: possible inclusion of patients with asthma and inconsistent outcome measures. The aim of the study was to determine the efficacy of prednisolone in recovery from acute bronchiolitis who have a family history of atopy. Material \& Methods: This randomized double blind placebo controlled trial (RCT) was conducted in the department of pediatrics Dhaka Medical College Hospital (DMCH) from July 2008 to June 2010. Sixty (60) bronchiolitis patients having family history of atopy were included in his study. Prednisolone and placebo were packaged in identical envelops with separate code number given by the guide and the code number were recorded in a preformed questionnaire. The trial was so planned that neither the parents nor the investigator were aware of group allocation. The collected data were analyzed thoroughly by SPSS program version of 16.0 software. Informed written consent from parents or legal guardians was taken and ethical clearance was obtained from the ethical review committee of Dhaka Medical College to conduct the research works. Results: In our study, mean age of the patients of this series were 3.68 months $( \pm 1.29 \mathrm{SD})$ and 3.52 month's $( \pm 1.1 \mathrm{SD})$ in prednisolone and placebo group respectively. Use of accessory muscle score was assessed twice at 8 am and $8 \mathrm{pm}$ each day for three days. On first assessment at day 1 the score was similar in both the treatment groups $(\mathrm{P}>.05)$. More people in Prednisolone arm recovered within 3 days then the placebo group. The difference is statistically significant $(\mathrm{P}<.01)$. Conclusion: Three-day oral prednisolone treatment was effective in accelerating clinical recovery (Fast breathing, use of accessory muscle, wheezing) in acute bronchiolitis cases who had family history of atopy.
\end{abstract}

Keywords: Prednisolone, Placebo, Atopy, Bronchiolitis, Respiratory

\section{Introduction}

Acute bronchiolitis is a condition where patients presents with problems such as breathing complications, cough, poor feeding, and bad temper and, in the exact early, apnea. All these clinical features, along with cough and crepitation's on auscultation syndicate to complete the diagnosis. Bronchiolitis usually is observed in babies aged 3-6 months 
[1]. Bronchiolitis come about in connotation with virusrelated contagions and is seasonal, with highest incidence in the winter time at what time such viruses are prevalent in the public. Re-infection throughout a particular time of year is probable [2]. Meanwhile, RSV is linked with merely $75 \%$ of bronchiolitis cases, it might be projected that about a third of all babies will grow bronchiolitis (from all viruses) in their first year of birth. In Scotland this interprets to almost 15,000 newborns [3]. Established on Scottish disease record in the years 2001 to 2003 a mean of 1,976 kids for each year (aged up to 12 months) were admitted to hospital with bronchiolitis as per the major diagnosis [4]. Management of bronchiolitis have several debates. Maximum trials of bronchiolitis treatment agonize from 2 restraints: likely addition of patients with asthma and unpredictable outcome trials. Study on out of 225 children 5 trials of nebulized epinephrine, have been published in the last decade. All have exposed clinical development in actions for example respiratory rate, wheezing, retractions, hospital admission rates, and time of hospital stay [5]. Demonstration of atopy amongst babies with RSV bronchiolitis would disclose a preexistent disorder accountable for the bronchiolitis and repeated wheezing. The occurrence of arrivals for case in point subtle rhinitis, atopic dermatitis, and asthma, along with sensitization contrary to joint ecological antigens and eosinophilia, are set up in atopic personalities. Such occurrences have been inspected in kids with RSV bronchiolitis. Regarding frequent wheezing, in a longitudinal study of Stein et al [6], established that the relationship between RSV and improved threat of repeated wheezing was liberated of an allergic sensitization. Nevertheless, in previous reports, atopic kids seemingly had a advanced chance of facing frequent wheezing after RSV bronchiolitis than non-atopic babies [7]. Many authors have tried to classify an indicator associated to atopy based on this, that look as if throughout bronchiolitis and that can guess which kids will grow repeated wheezing. The researchers dignified RSV-specific IgE, amount of eosinophils in the severe stage of the sickness, ECP in nasal secretions, and myeloperoxidase, and then connected these with the medical sequence [8]. Still, up to the present time, no study has been definite. About the use of complete corticosteroids in bronchiolitis meta-analysis recommended a statistically substantial upgrading in medical signs \& length of hospital stay [9]. Conversely, there are no small or extended term medical benefits from the supervision of nebulized corticosteroids in the severe stage of RSV bronchiolitis [10].

\section{Objectives}

1) General objective:

To determine the efficacy of prednisolone in recovery from acute bronchiolitis who have a family history of atopy.

2) Specific Objectives:

a) To determine the efficacy of prednisolone in recovering from acute bronchiolitis by MRDAI score.

b) To determine the influence of prednisolone on the duration of oxygen requirement. c) To determine the influence of prednisolone on the length of hospital stay.

\section{Methodology and Materials}

This randomized double blind placebo controlled trial (RCT) was conducted in the department of pediatrics Dhaka Medical College Hospital (DMCH) from July 2008 to June 2010. A total of 60 bronchiolitis patients having family history of atopy were included in his study according to following the inclusion and exclusion criteria. Parents of those who consented to participate were allocated with one of the treatment arm randomly by box of eight lottery method. Recruitment was continued until the desired number of subject was taken. Group allocation to either prednisolone or placebo group were done by lottery method, i.e., the mother/father picked up a sealed, encoded envelop from a box of eight; each containing 12 to 15 small packets of powdered Prednisolone or placebo. Each small packet contained $5 \mathrm{mg}$ powdered prednisolone tablet or $5 \mathrm{mg}$ flour as placebo. Prednisolone and placebo were packaged in identical envelops with separate code number given by the guide and the code number were recorded in a preformed questionnaire. The trial was so planned that neither the parents nor the investigator were aware of group allocation. Prednisolone $(2 \mathrm{mg} / \mathrm{kg} /$ day $)$ was given after crushing \& making it powder orally or through NG tube for three consecutive days in 2-3 divided doses. The same amount of flour (placebo) was given in the same way. Nutrition through NG tube feeding or IV $10 \%$ dextrose in $0.225-0.45 \%$ saline where applicable. Nebulized salbutamol $(0.15 \mathrm{mg} / \mathrm{kg} / \mathrm{dose})$ 6 hourly for 3 days. Following randomization and intervention, cases were monitored by modified respiratory distress assessment instrument (MRDAI) score twice daily for 3 days. Structured questionnaire was used. The collected data were analyzed thoroughly by SPSS program version of 16.0 software. Informed written consent from parents or legal guardians was taken and ethical clearance was obtained from the ethical review committee of Dhaka Medical College to conduct the research works.

\section{1) Inclusion Criteria}

a) Runny nose with or without fever followed by first attack of wheeze in a child aging 1 month to 2 years occurring within a span of 7 days.

b) Tachypnea, Chest in drawing.

c) Child with family history (father/ mother /sister/brother) of atopy (allergic rhinitis, allergic conjunctivitis, eczema, asthma, seborrheic dermatitis)

d) Healthy previously.

2) Exclusion Criteria

a) Recurrent attacks of wheeze.

b) Severe malnutrition.

c) Associated second illness; i.e., heart failure, congenital heart disease, Down's syndrome etc.

d) Complications: Pneumonia, Pneumothorax etc.

e) Congenital airway disease: Laryngomalacia, Tracheomalacia etc. 
f) Patients who had treated previously with prednisolone and/or bronchodilator.

\section{Results}

Average age in two comparing group is similar (months in Prednisolone and months in placebo group). Sex distribution is also similar in two group ( $\mathrm{P}>.05)$. Allergic rhinitis, Asthma and eczema were prevalent in the study subjects and the distribution is similar in both the group of subjects. $\mathrm{SPO}_{2}$ and $\mathrm{TLC} / \mathrm{mm}^{3}$ was also found to be similar in two groups (Table 1). Comparison of respiratory rate score in Prednisolone and Placebo groups were done through independent $t$ test. Respiratory rate was assessed twice at 8 am and $8 \mathrm{pm}$ each day for three days. On first assessment at day 1 the rate of respiration was similar in both the treatment groups $(\mathrm{P}>.05)$. In the next assessment onward up to three days significant difference emerged in rate of respiration in two group. The response was significantly better in Prednisolone group $(\mathrm{P}<.01)$ (Table 2). Use of accessory muscle score was assessed twice at 8 am and $8 \mathrm{pm}$ each day for three days. On first assessment at day 1 the score was similar in both the treatment groups $(\mathrm{P}>.05)$. In the next assessment onward up to three days significant difference emerged in use of accessory muscle two groups. The response was significantly better in Prednisolone group $(\mathrm{P}<.01)$ (Table 3$)$. The cyanosis score in Prednisolone and Placebo groups were done through independent $t$ test. Cyanosis score was assessed twice at 8 am and $8 \mathrm{pm}$ each day for three days. On each assessment at day 1 to 3 the score was similar in both the treatment groups $(\mathrm{P}>.05)$ (Table 4). Comparison of the auscultatory finding score in Prednisolone and placebo groups were done through independent $\mathrm{t}$ test. Auscultatory finding was taken twice at 8 am and $8 \mathrm{pm}$ each day for three days. On first three assessments on day 1 to 2 , the score was similar in both the treatment groups $(\mathrm{P}>.05)$. However significant difference emerged in last three assessments on day 2 and $3(\mathrm{P}<.05)$ (Table 5). Table 6 shows the distribution of the respondents by average time of oxygen treatment required. Requirement of oxygen is more in placebo arm than the Prednisolone. Shows the distribution of the participants by type of treatment and of duration of hospital stay (Table 7, Table 8). More people in Prednisolone arm recovered within 3 days then the placebo group. The difference is statistically significant $(\mathrm{P}<.01)$.

Table 1. Comparison of baseline characteristics $(n=60)$.

\begin{tabular}{|c|c|c|c|}
\hline & \multicolumn{2}{|l|}{ Treatment group } & \multirow{2}{*}{ P value } \\
\hline & Prednisolone $(\mathrm{n}=\mathbf{3 0})$ & Placebo $(n=30)$ & \\
\hline Age in months (Mean $\pm \mathrm{SD}$ ) & $3.68 \pm 1.29$ & $3.52 \pm 1.11$ & $\mathrm{p}=.323$ \\
\hline \multicolumn{4}{|l|}{ Sex } \\
\hline Male & $16(53.3)$ & $20(66.7)$ & $\mathrm{P}>.05$ \\
\hline Female & $14(46.7)$ & $10(33.3)$ & $\mathrm{P}>.05$ \\
\hline \multicolumn{4}{|l|}{ Compliments } \\
\hline Fever & $28(93.3)$ & $29(96.7)$ & $\mathrm{P}>.05$ \\
\hline Feeding difficulty & $25(83.3)$ & $23(76.7)$ & $\mathrm{P}>.05$ \\
\hline \multicolumn{4}{|l|}{ Family history of atopy } \\
\hline Allergic Rhinitis & $13(43.3 \%)$ & $16(53.3 \%)$ & $\mathrm{P}>.05$ \\
\hline Asthma & $8(26.6 \%)$ & $6(20 \%)$ & $\mathrm{P}>.05$ \\
\hline Allergic conjunctivitis & $2(6.7 \%)$ & $1(3.3 \%)$ & $\mathrm{P}>.05$ \\
\hline Eczema & $7(23.3 \%)$ & $7(23.3 \%)$ & $\mathrm{P}>.05$ \\
\hline $\mathrm{SPO}_{2}$ & $89 \%$ & $87 \%$ & $\mathrm{P}>.05$ \\
\hline $\mathrm{TLC} / \mathrm{mm} 3$ & 9800 & 9580 & $\mathrm{P}>.05$ \\
\hline
\end{tabular}

Table 2. Comparison of effect of Prednisolone with that of placebo in terms of respiratory rate score $(n=60)$.

\begin{tabular}{|c|c|c|c|c|c|c|}
\hline \multirow{2}{*}{ Day } & \multirow{2}{*}{ Time } & \multirow{2}{*}{ Intervention } & \multicolumn{4}{|c|}{ Respiratory rate } \\
\hline & & & Mean & SD & $\mathrm{t}$ & Pvalue \\
\hline \multirow{4}{*}{ Day1 } & \multirow{2}{*}{$8 \mathrm{AM}$} & Prednisolone & 2.93 & .254 & .460 & .647 \\
\hline & & Placebo & 2.90 & .305 & & \\
\hline & \multirow{2}{*}{$8 \mathrm{PM}$} & Prednisolone & 2.67 & .479 & -2.249 & .028 \\
\hline & & Placebo & 2.90 & .305 & & \\
\hline \multirow{4}{*}{ Day2 } & \multirow{2}{*}{$8 \mathrm{AM}$} & Prednisolone & 2.37 & .556 & -4.182 & .000 \\
\hline & & Placebo & 2.87 & .346 & & \\
\hline & \multirow{2}{*}{$8 \mathrm{PM}$} & Prednisolone & 2.03 & .556 & -5.361 & .000 \\
\hline & & Placebo & 2.73 & .450 & & \\
\hline \multirow{4}{*}{ Day3 } & \multirow{2}{*}{$8 \mathrm{AM}$} & Prednisolone & 1.43 & .679 & -6.070 & .000 \\
\hline & & Placebo & 2.50 & .682 & & \\
\hline & \multirow{2}{*}{8 PM } & Prednisolone & 1.23 & .626 & -6.943 & .000 \\
\hline & & Placebo & 2.40 & .675 & & \\
\hline
\end{tabular}


Table 3. Comparison of efficacy of Prednisolone with that of placebo in terms of accessory muscle use score through independent $t$ test ( $n=60)$.

\begin{tabular}{|c|c|c|c|c|c|c|}
\hline \multirow{2}{*}{ Day } & \multirow{2}{*}{ Time } & \multirow{2}{*}{ Intervention } & \multicolumn{4}{|c|}{ Use of accessory muscle } \\
\hline & & & Mean & SD & $\mathbf{t}$ & P value \\
\hline \multirow{4}{*}{ Day1 } & \multirow{2}{*}{$8 \mathrm{AM}$} & Prednisolone & 2.57 & .504 & -1.351 & .182 \\
\hline & & Placebo & 2.73 & .450 & & \\
\hline & \multirow{2}{*}{$8 \mathrm{PM}$} & Prednisolone & 2.17 & .461 & -4.455 & .000 \\
\hline & & Placebo & 2.70 & .466 & & \\
\hline \multirow{4}{*}{ Day2 } & \multirow{2}{*}{$8 \mathrm{AM}$} & Prednisolone & 1.70 & .651 & -2.516 & .015 \\
\hline & & Placebo & 2.03 & .320 & & \\
\hline & \multirow{2}{*}{$8 \mathrm{PM}$} & Prednisolone & 1.23 & .626 & -4.226 & .000 \\
\hline & & Placebo & 1.83 & .461 & & \\
\hline \multirow{4}{*}{ Day3 } & \multirow{2}{*}{$8 \mathrm{AM}$} & Prednisolone & .73 & .740 & -4.710 & .000 \\
\hline & & Placebo & 1.57 & .626 & & \\
\hline & \multirow{2}{*}{$8 \mathrm{PM}$} & Prednisolone & .50 & .777 & -4.642 & .000 \\
\hline & & Placebo & 1.40 & .724 & & \\
\hline
\end{tabular}

Table 4. Comparison of efficacy of Prednisolone with that of placebo in terms of cyanosis score through independent t test ( $n=60)$.

\begin{tabular}{|c|c|c|c|c|c|c|}
\hline \multirow{2}{*}{ Day } & \multirow{2}{*}{ Time } & \multirow{2}{*}{ Intervention } & \multicolumn{4}{|c|}{ Cyanosis score } \\
\hline & & & Mean & SD & t & P value \\
\hline \multirow{4}{*}{ Day1 } & \multirow{2}{*}{$8 \mathrm{AM}$} & Prednisolone & .73 & .583 & \multirow[t]{2}{*}{-.894} & \multirow[t]{2}{*}{.375} \\
\hline & & Placebo & .87 & .571 & & \\
\hline & \multirow{2}{*}{$8 \mathrm{PM}$} & Prednisolone & .43 & .626 & \multirow[t]{2}{*}{-.992} & \multirow[t]{2}{*}{.325} \\
\hline & & Placebo & .60 & .675 & & \\
\hline \multirow{4}{*}{ Day2 } & \multirow{2}{*}{$8 \mathrm{AM}$} & Prednisolone & .13 & .434 & \multirow[t]{2}{*}{-.317} & \multirow[t]{2}{*}{.753} \\
\hline & & Placebo & .17 & .379 & & \\
\hline & \multirow{2}{*}{$8 \mathrm{PM}$} & Prednisolone & .07 & .254 & \multirow[t]{2}{*}{-.460} & \multirow[t]{2}{*}{.647} \\
\hline & & Placebo & .10 & .305 & & \\
\hline \multirow{4}{*}{ Day3 } & \multirow{2}{*}{$8 \mathrm{AM}$} & Prednisolone & .03 & .183 & \multirow[t]{2}{*}{-1.027} & \multirow[t]{2}{*}{.309} \\
\hline & & Placebo & .10 & .305 & & \\
\hline & \multirow{2}{*}{$8 \mathrm{PM}$} & Prednisolone & .03 & .183 & \multirow[t]{2}{*}{-.584} & \multirow[t]{2}{*}{.561} \\
\hline & & Placebo & .07 & .254 & & \\
\hline
\end{tabular}

Table 5. Comparison of efficacy of Prednisolone with that of placebo in terms of auscultatory finding score through independent $t$ test ( $n=60)$.

\begin{tabular}{|c|c|c|c|c|c|c|}
\hline \multirow{2}{*}{ Day } & \multirow{2}{*}{ Time } & \multirow{2}{*}{ Intervention } & \multicolumn{4}{|c|}{ Auscultatory Finding } \\
\hline & & & Mean & SD & $t$ & P value \\
\hline \multirow{4}{*}{ Day1 } & \multirow{2}{*}{$8 \mathrm{AM}$} & Prednisolone & 2.47 & .507 & 1.325 & .190 \\
\hline & & Placebo & 2.30 & .466 & & \\
\hline & \multirow{2}{*}{$8 \mathrm{PM}$} & Prednisolone & 2.20 & .484 & .000 & 1.000 \\
\hline & & Placebo & 2.20 & .407 & & \\
\hline \multirow{3}{*}{ Day2 } & $8 \mathrm{AM}$ & Prednisolone & 1.90 & .403 & -1.918 & .060 \\
\hline & \multirow{2}{*}{$8 \mathrm{PM}$} & Prednisolone & 1.53 & .629 & -3.882 & $.000 *$ \\
\hline & & Placebo & 2.03 & .320 & & \\
\hline \multirow{4}{*}{ Day3 } & \multirow{2}{*}{$8 \mathrm{AM}$} & Prednisolone & 1.17 & .648 & -4.917 & $.000 *$ \\
\hline & & Placebo & 1.87 & .434 & & \\
\hline & \multirow{2}{*}{$8 \mathrm{PM}$} & Prednisolone & .57 & .774 & -6.137 & $.000 *$ \\
\hline & & Placebo & 2.47 & .507 & & \\
\hline
\end{tabular}

Table 6. Comparison of the duration of oxygen treatment $(n=60)$.

\begin{tabular}{lllll}
\hline \multirow{2}{*}{ Intervention } & \multicolumn{4}{l}{ duration of oxygen treatment } \\
\cline { 2 - 5 } & Mean & SD & Range & t \\
\hline Prednisolone & 13.70 & 6.727 & $5-30$ & -4.183 \\
Placebo & 24.10 & 11.839 & $10-70$ & $<.001$ \\
\hline
\end{tabular}

Table 7. Distribution of the participants by type of treatment and of duration of hospital stay $(n=60)$.

\begin{tabular}{llll}
\hline \multirow{2}{*}{ Hospital stay } & Treatment arm & & P value \\
\cline { 2 - 3 } & Prednisolone & Placebo & $5(16.7)$ \\
\hline Within 3 days & $24(80.2)$ & $25(83.3)$ & Chi sq $=26.7 \mathrm{P}=.0001$ \\
$>3$ days & $6(19.8)$ & $30(100.0)$ & \\
Total & $30(100.0)$ & \\
\hline
\end{tabular}


Table 8. Comparison of duration of hospital stay $(n=60)$.

\begin{tabular}{llll}
\hline \multirow{2}{*}{ Treatment arm } & Hospital stay & T test, P value \\
\cline { 2 - 3 } & Mean (SD) & Range & \multirow{2}{*}{$-6.6, \mathrm{P}=0.000^{*}$} \\
\hline Prednisolone & $3.3(0.64)$ & $3-5$ & $3-6$ \\
Placebo & $4.6(0.89)$ & & $3-6$ \\
\hline
\end{tabular}

\section{Discussion}

Acute bronchiolitis is the leading cause of hospitalization in children below 2 years of age. Males are predominantly affected than female. Mean age of the patients of this series were 3.68 months $( \pm 1.29 \mathrm{SD})$ and 3.52 month's $( \pm 1.1 \mathrm{SD})$ in prednisolone and placebo group respectively. All of the patient's in this study presented with respiratory distress, cough, fast breathing, chest in drawing and wheeze. Kabir et al [11] observed clinical presentation of bronchiolitis almost similar to what were observed in present study. Bronchiolitis is the inflammatory disease of small airways which results in hypoxia [12]. Hypoxic children are five times more likely to die than non-hypoxemic children. In the present study respiratory rate, accessory muscle use, cyanosis and auscultatory findings were observed as clinical variables. Fast breathing is a useful predictor of hypoxemia [13]. An increase in respiratory rate is one of the physiological response to hypoxia from acute bronchiolitis. In this study oral prednisolone treatment significantly decreased respiratory rate $(\mathrm{p}<0.01)$ within 2 days. In an earlier study on acute bronchiolitis showed that oral prednisolone significantly decreased fast breathing $(\mathrm{p}<0.05)$ within 72 hours of treatment in comparison to placebo group12. Use of accessory muscle is a best predictor for respiratory distress and hypoxemia in children with acute bronchiolitis. In present study oral prednisolone significantly declined accessory muscle score $(p<0.01)$ within 2 days of treatment. Similar observation was found in a study where prednisolone improved chest in drawing $(\mathrm{p}<0.05)$ at 3 days of treatment14. Measurement of $\mathrm{O} 2$ saturation by pulse oximeter is most reliable method to detect hypoxia in bronchiolitis. In the present study mean time of $\mathrm{O} 2$ requirements significantly declined in prednisolone group 13.7 and 24.1 in placebo group $(\mathrm{p}<0.05)$. Almost similar observation were seen by a group of researchers [14]. In similar study like the current one, by Woensel et al [15] all patients were RSV-positive and had atopy. Moreover, they all had bronchiolitis, well-defined as acute tachypnea, wheezing and reduced breath sounds, cyanosis, or the usage of accessory respiratory muscles, in the existence of a virus-related contagion. They observed a meaningfully smaller period of hospital stay in automatically ventilated patients who has got the prednisolone, even though the number of patients was lesser. The sign score reduced meaningfully sooner in the superior group of patients with Prednisolone, who were not automatically ventilated. Corticosteroids have been used for many years in the management of bronchiolitis, asthmatic bronchitis, and wheezing in babies, on the theory that they could decrease a bronchiolar swelling and bronchiolar manic reactivity. In this present study, systemic corticosteroid was selected as an alternative of inhaled corticosteroid as the indecision in regard to the acceptance of inhaled corticosteroid. There are a quantity of likely clarifications for the absence of result of corticosteroids in RSV infection. The pathophysiology may vary from that of asthma, where the result is well-documented [16]. The time of life of the babies may regulate the reaction to corticosteroid management [17]. Length of hospital stay is strongly correlated with resolution of symptoms. In the present study prednisolone significantly reduced hospital stay $(\mathrm{p}<0.001)$. More patient in prednisolone group discharged at 3 days of treatment. Similar observation was seen in another study, mean duration of hospital stay was shorter in prednisolone group [18]. As a result, it could prevent the deterioration of lung functions and reduce the sensitivity of triggers [19]. Although multiple studies have failed to demonstrate efficacy of corticosteroids in bronchiolitis, in the current study all the patients of both groups presented with first attack of wheeze having family history of atopy treated with prednisolone showed a significant clinical improvement and thus reduced hospital stay.

\section{Limitations of the Study}

1. Sample size was small.

2. Multi-center study was not preformed.

\section{Conclusion and Recommendations}

Three day oral prednisolone treatment was effective in accelerating clinical recovery (Fast breathing, use of accessory muscle, wheezing) in acute bronchiolitis cases who had family history of atopy. Prednisolone treatment reduced the duration of $\mathrm{O}_{2}$ therapy and the length of hospital stay significantly and was found safe. A 3 days course of oral prednisolone should be given to an acute bronchiolitis cases who have family history of atopy. Metacentric study should be done with larger sample size.

\section{References}

[1] Paediatric Society of New Zealand. Wheeze and chest infection in infants under 1 year. Wellington: The Society; 2005. [Cited22August2006].

[2] Papadopoulos NG, Moustaki M, Tsolia M, Bossios A, Astra E, Prezerakou A, et al. Association of rhinovirus infection with increased disease severity in acute bronchiolitis. Am J Respir Crit Care Med 2002; 165: 1285-89?

[3] Glezen WP, Taber LH, Frank AL, Kasel JA. Risk of primary infection and reinfection with respiratory syncytial virus. Am J Dis Child 1986; 140 (6): 543-6. 
[4] ISD Scotland. Number of hospital discharges with bronchiolitis in children 0-24 months in Scotland for the years ending December 2001 - 2003. [Statistical data]. Edinburgh: ISD Scotland; 2006.

[5] Josephine R. Welliver and Robert C. Welliver. Bronchiolitis. Pediatr. Rev. 1993; 14; 134-139.

[6] Pullan CR, Hey EN - Wheezing, asthma, and pulmonary dysfunction 10 years after infection with respiratory syncytial virus in infancy. Brit Med J 1982; 284: 1665-9.

[7] Sims DG, Gardner PS, Weightman D et al. - Atopy does not predispose to RSV bronchiolitis or postbronchiolitic wheezing. Brit Med J 1981; 282: 2086-88.

[8] Ehlenfield DR, Cameron K, Welliver RC - Eosinophilia at the time of respiratory syncytial virus bronchiolitis predicts childhood reactive airway disease. Pediatrics 2000; 105: 79-83.

[9] Csonka P, Kaila M, Laipapala P, Iso Mustajardi M, Vesikari T, Ashorn P. Oral prednisolone in the acute management of children age 6-35 months with viral infection induced lower airway disease: a randomized placebo - controlled trial. $J$ Pediatr 2003; 143 (6): 700-702.

[10] Kuyucu S, Unal S, Kuyucu N, Yilgor E. Additive effects of dexamethasone in nebulized salbutamol or L - epinephrine treated infants with ac. Bronchiolitis. Pediatr int. 2004; 46 (5): 539-544.

[11] Kabir ARML, Amin R, Morsed AKMA, Shirin M. update on a recent epidemic. The Orion 2002; 12: 9-10.

[12] Sayeed A. Efficacy of oral prednisolone in the treatment of acute bronchiolitis: A randomized control trial [Dissertation]. Dhaka: BCPS; 2005.

[13] Smyth A, Carty H, Hart CA. Clinical predictors of hypoxemia in children with pneumonia. Ann Trop Pediatr 1998; 18: 31-40.

[14] Klassen TP, Sutcliff T, Watters LK, Wells GA, Alien UD, Li MM. Dexamethasone in salbutamol-treated in patients with acute bronchiolitis: a randomized, controlled trial. J Pediatr 1997; 130: 191-196.

[15] Van Woensel JB, Wolfs TF, van Alderen WM, Brand PL, Kimpen JL Randomized double-blind placebo controlled trial of prednisolone in children admitted to hospital with respiratory syncytial virus bronchiolitis. Thorax 1997; 52: 634-637.

[16] Noble V, Murray M, Webb MSC, Alexander J, Swarbrick AS, Milner AD Respiratory status and allergy nine to ten years after acute bronchiolitis. Arch Dis Child 1997; 76: 315-319.

[17] Martinez FD, Morgan WJ, Wright AL, Holberg CJ, Taussig LM, Group Health Medical Associates Personnel Diminished lung function as a predisposing factor for wheezing respiratory illness in infants. N Engl J Med 1988; 319: 112117.

[18] Patel H, Platt R, Lozano JM, et al. Glucocorticoids for acute viral bronchiolitis in infants and young children (Cochran Review). In: The Cochrane Library, issue 3. Chichester, UK: John Wiley \& Sons; 2004.

[19] Asthma Association, Bangladesh. National Guidelines Asthma, Bronchiolitis, COPD. $3^{\text {rd }}$ Edition. 2005. 